\title{
Airframe Technology Development for Next Generation Launch Vehicles
}

\author{
David E. Glass \\ MS 173, NASA Langley Research Center \\ Hampton, VA 23681-2199 \\ (757) 864-5423, david.e.glass@nasa.gov
}

\begin{abstract}
$\underline{\text { Abstract }}$
The Airframe subproject within NASA's Next Generation Launch Technology (NGLT) program has the responsibility to develop airframe technology for both rocket and airbreathing vehicles for access to space. The Airframe sub-project pushes the state-ofthe-art in airframe technology for low-cost, reliable, and safe space transportation. Both low and medium technology readiness level (TRL) activities are being pursued. The key technical areas being addressed include design and integration, hot and integrated structures, cryogenic tanks, and thermal protection systems. Each of the technologies in these areas are discussed in this paper.
\end{abstract}

\section{$\underline{\text { Introduction }}$}

NASA's Integrated Space Transportation Plan (ISTP) includes (a) Space Shuttle Upgrades, (b) the Orbital Space Plane, and (c) the Next Generation Launch Technology (NGLT) program. NGLT is focused on Propulsion, Systems Analysis and Integration, and Launch Systems Technology. Within Launch Systems Technology, are three projects, one of which is Vehicle Systems Research and Technology (VSR\&T). The Airframe technology development is performed within the VSR\&T project. The focus herein is the Airframe technology development. (As a result of NASA's refocus on exploration, the ISTP has been modified, and the Airframe subproject, as well as much of NGLT, has been cancelled effective the end of FY04.)

The goal of the Airframe technology development is to develop and demonstrate airframe technologies for launch vehicles providing significant increases in performance margin that result in reductions in cost of space transportation systems while dramatically improving the safety and operability of those systems. There are three main objectives for the Airframe R\&T:

- Increased weight margin

- Increased combined loads margin

- Thermal

- Structural

- Acoustic
- Increased operational margin

The technical challenges associated with achieving the Airframe goals and objectives for launch vehicles include low drag, minimum weight, flight from Mach 0-25-0 (takeoff, flight to LEO, deorbit, and landing), high volumetric efficiency, and high dynamic pressure flight.
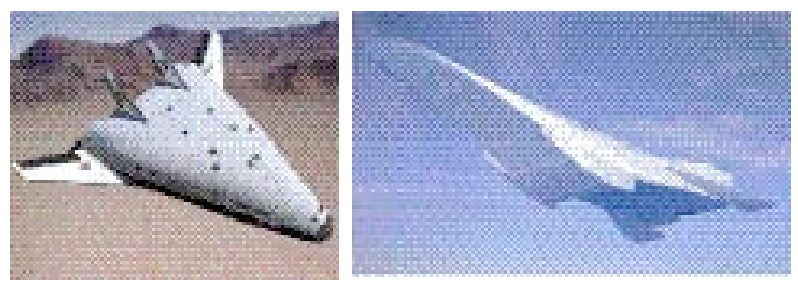

Fig. 1. Example of rocket versus airbreather single stage to orbit (SSTO) concepts.

Technical challenge differences between a rocket and airbreather airframe are sometimes less obvious than those for just the propulsion system, but they are no less important or significant. Examples of rocket versus airbreathing propulsion vehicles are shown in Fig. 1. The TPS for airbreathers may be driven by the long ascent time and the resulting high integrated heat load; however, high descent heating rates must also be investigated. Because low-drag, sharp leading edges are often a requirement, a much higher stagnation heat flux results than for the blunt leading edges often utilized on rocket-based propulsion vehicles. Also, the need for low drag leads one to consider conformal tanks for airbreathers versus cylindrical tanks for rockets. The structure is significantly different, with airbreathers often having highly loaded wings, hot control surfaces, and an airframe that is highly integrated with the propulsion system. In addition, landing gear on an airbreather is sized for a fully loaded (full fuel tank) takeoff versus a lightly loaded (empty tanks) landing for a rocket.

The approach to address the airframe technical challenges is to focus on structures and materials technology development that includes tasks in the areas of Design and Integration, Hot and Integrated Structures,

The use of trademarks or names of manufacturers in this paper is for accurate reporting and does not constitute an official endorsement, either expressed or implied, of such products or manufacturers by the National Aeronautics and Space Administration. 
Cryogenic Tanks, and Thermal Protection Systems. A mix of medium and low TRL technologies is being addressed by the project. The approaches taken to address the technical challenges and increase performance margin and reusability include:

- Composite tanks

- Conformal tanks

- Thin control surfaces

- Hot structures

- Leading edges

- Acreage thermal protection systems

- High fidelity design and analysis tools

- Dynamic seals

- Airframe health monitoring

- Actively cooled structures

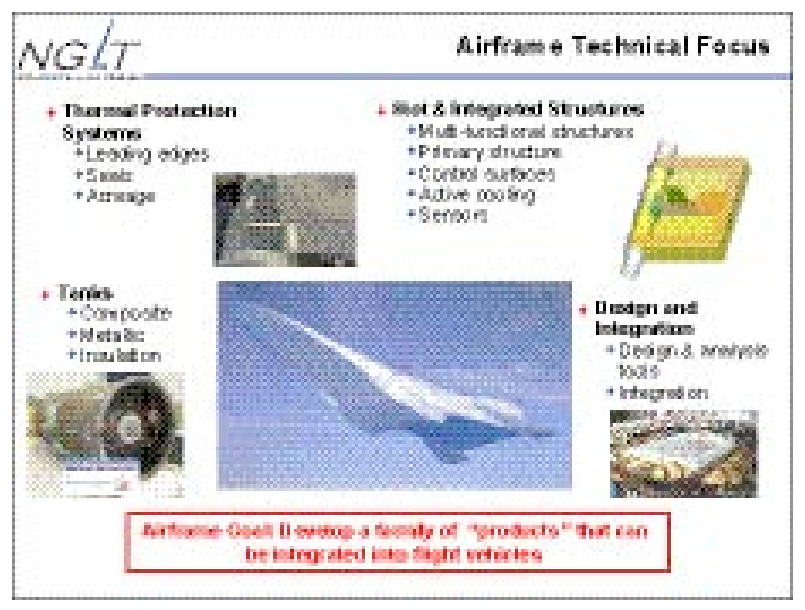

Fig. 2. Airframe technical focus.

The Airframe technical focus is illustrated in Fig. 2. In the Design and Integration element, both Design and Analysis Tools and Integration, such as TPS/tank integration are being developed. The Hot and Integrated Structures element includes Multi-Functional Structures, Primary Structures, Control Surfaces, and Sensors. The Tanks element includes Composite Tanks, Metallic Tanks, and Insulation. The Thermal Protections Systems element includes Leading Edges, Seals, and Acreage TPS.

\section{Description of Tasks}

The FY04 Airframe R\&T consists of four elements which are focused on developing technology for both rocket and airbreathing launch vehicles. The four elements are Design and Integration, Hot and Integrated Structures, Tanks, and Thermal Protections Systems. Each of the tasks in these elements is discussed below.

\section{Design and Integration}

The objectives of the Design and Integration element include development of design and analysis tools to provide accurate and rapid airframe structure design and the integration of airframe structure and TPS. The Analysis and Design Methods task has efforts focused on thermal acoustic fatigue, probabilistic design, aerothermal analysis, and reliability analysis for cryogenic tanks. The TPS/Tank Integration task is focused on issues associated with integration of TPS on a cryogenic tank.

The objective of the Analysis and Design Methods task is to develop and validate the design and analysis tools necessary to accurately design an airframe structure that survives the combined loads of flight. The focus is on (a) developing a rapid, variable fidelity, methodology to integrate trajectory analysis with aero/aerothermal loads, TPS selection and sizing, and vehicle thermal response; (b) probabilistic design, (c) developing and validating the capability to predict thermo-acoustic fatigue from combined loads (test article shown in Fig. 3), and (d) developing validated analytical tools for damage tolerance to design composite launch vehicle structures.

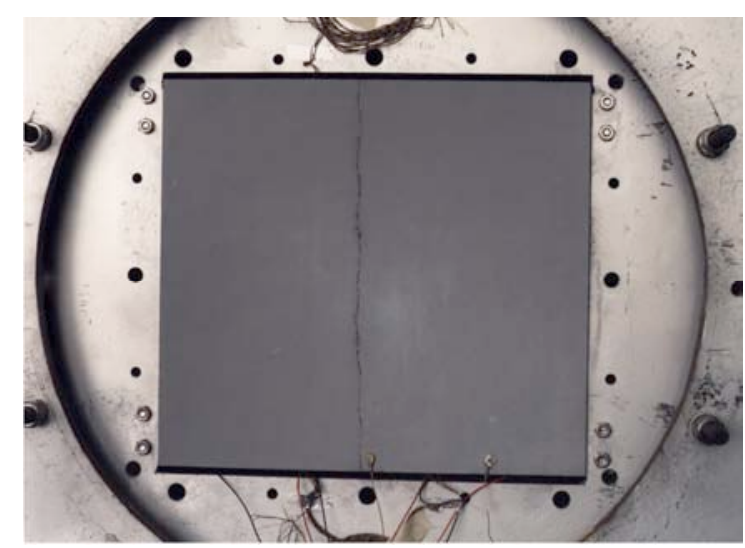

Fig. 3. Composite panel with thermal acoustic fatigue generated failure.

The objective of the probabilistic design sub-task was to develop the technology for carrying out airframe design in which design requirements are specified in terms of the probability of occurrence of component and/or system failure. For example, the goal could be to obtain a minimum weight design for which the probability of excessive stress is less than a specified amount. The task involves quantifying and accounting for uncertainties. Preliminary studies have shown that this approach provides designs that are superior to de- 
signs obtained using conventional factors of safety to account for uncertainties.

The first study was to compare two methods of accounting for uncertainties - probabilistic and possibilistic (a method similar to fuzzy logic). ${ }^{1-3}$ The problem studied was a bonded joint with a crack. The study examined the effect of a geometrically nonlinear analysis, showed the effect of two failure modes (fracture in the adhesive and material strength failure in the strap), showed the effect of correlated random variables, and illustrated several computation techniques. Whereas the first study involved analysis with uncertainties, the second study involved reliability-based design. This second study was to determine the thickness distribution of a minimum weight plate-like wing so that it would have a specified probability of meeting flutter and strength requirements. That probability is the reliability. Uncertainties were assumed to occur in the failure stress, the flutter analysis, the pressure load, and the thickness distribution.

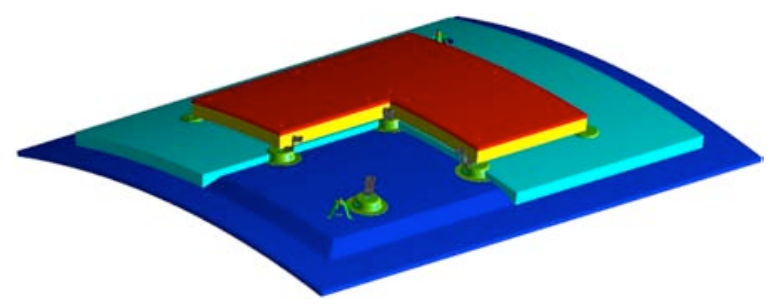

Fig. 4. Schematic diagram of metallic TPS integrated onto composite tank panel via stanchions.

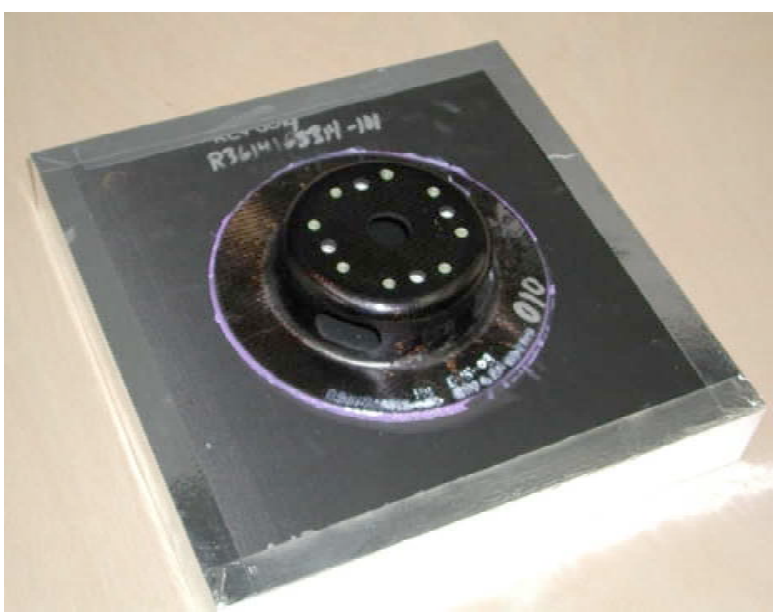

Fig. 5. Photograph of stanchion bonded to composite for adhesive testing.

The goal of the Thermo-Acoustic Fatigue subtask was to develop and validate a capability to predict thermo-acoustic fatigue from combined loads. ${ }^{4-6}$ The target airframe components included the fuselage, appenage and other structures subjected to high heating and vibro-acoustic loading, and structures otherwise susceptible to high cycle fatigue. Therefore, the ability to analyze geometrically complicated structures was of paramount importance. Further, the ability to do so in a computationally efficient manner was critical so that the tools developed could be applied during the design process. These two requirements led to the early decision to further develop and validate the NASA Langley analysis code ELSTEP.

The objective of the TPS/Tank Integration task is to develop the capability to design and demonstrate a fully integrated airframe structure. The current focus of this task is the integration of metallic TPS onto a composite cryogenic tank. Curved metallic TPS panels are being fabricated which will be integrated onto a $4 \mathrm{ft}$ $\times 6 \mathrm{ft}$ composite tank section (Fig. 4). The metallic TPS will be integrated onto the panel via composite stanchions, shown in Fig. 5. After the metallic TPS panels are integrated onto the panel, the integrated system will be ready for thermal testing.

\section{$\underline{\text { Hot and Integrated Structures }}$}

The next element in Airframe is Hot and Integrated Structures, with a focus on polymer matrix composite (PMC), metal matrix composite (MMC), and ceramic matrix composite (CMC) materials development for application to structures, and the development of wall structural concepts. Efficient and reliable hot wing structures with low maintenance and fabrication costs are part of the long-range goals of this element. This element consists of five tasks. Integrated Airframe Structures is focused on the long term development and validation of structural systems that show the best potential for a "wall that does it all." The CMC Control Surfaces task is focused on reproducible CMC materials with improved mechanical reliability and cyclic durability for control surfaces. Next, the Metallic Materials for Hot Structures task is focused on advanced gamma TiAl and intermetallic MMC's for $1200^{\circ} \mathrm{F}$ $1500^{\circ} \mathrm{F}$ applications, novel lightweight metallic systems for $1500^{\circ} \mathrm{F}-2000^{\circ} \mathrm{F}$ applications, efficient joining processes, and lightweight protective coatings. The High Temperature PMC's task is focused on advanced hightemperature polymers for use as primary structures. Finally, the Fiber Optic Sensors task is focused on the development of high-temperature and multiparameter (temperature and strain) sensors.

The Integrated Airframe Structures task is focused on both hot and warm (insulated) structures and inte- 
grated fuselage/tank/TPS systems. The objective is to develop integrated multifunctional airframe structures that eliminate fragile external thermal protection systems and incorporate the insulating function within the structure. The approach taken to achieve this goal is to develop candidate hypersonic airframe concepts including structural arrangement, load paths, thermalstructural wall design, thermal accommodation features, and integration of major components; optimize thermalstructural configurations; and validate concepts through a building-block test program and generate data to improve and validate analytical and design tools.

The structural arrangements considered include both integral, where the tank carries internal and external loads, aerothermodynamic loads, and nonintegral, where the tank carries only internal pressure loads and the tank can expand and contract. An integrated wall construction is an approach, or design philosophy, where the entire structure (the tank, insulation, TPS, etc.) is designed together to account for thermal and mechanical loads. This task considers all options for an integrated structure, including TPS, cold structure, hot structure, tanks, insulation, and all types of material systems. An illustration of a truss core sandwich concept is shown in Fig. 6.

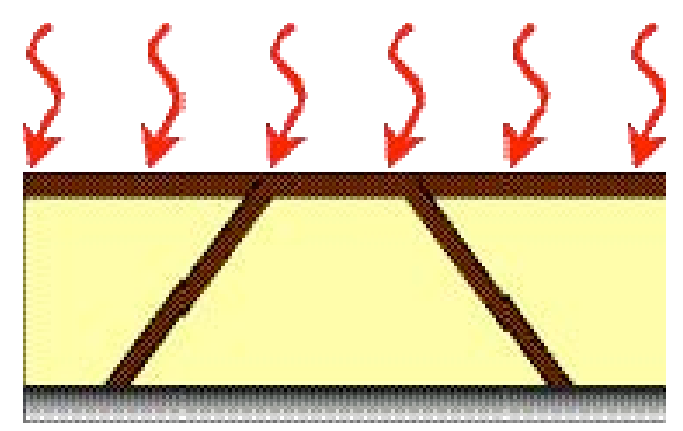

Fig. 6. Schematic of truss core sandwich concept.

The CMC Control Surfaces task is focused on improving the fabrication and cycle mission life of ceramic matrix composite (CMC) control surfaces. A high payoff application presently under study is a CMC control surface. In June 2001, Materials Research \& Design, Inc. (MR\&D) was awarded the NASA Next Generation Launch Technologies (NGLT) contract entitled "Design, Fabrication and Test of Ceramic Matrix Composite (CMC) Control Surface Structure and Joining Technology." The objectives of the contract were twofold: 1) to develop and demonstrate technologies associated with the joining of separate CMC control surface segments, and 2) to design, fabricate, and perform flight qualification testing of a CMC body flap control surface. The first objective is required when a given hot structure control surface is too large to be fabricated within single CMC processing facility. Relative to the second objective, the NASA/Boeing X37 long duration orbiting vehicle (LDOV) is a potential flight demonstration vehicle.

The contract was performed by a joint industry and government team lead by MR\&D, the prime contractor. For the subelement test articles, the industry participants included two separate fabrication teams. For one team, General Electric Company Power Systems Composites (GE PSC) of Newark, DE, was the partner responsible for the CMC fabrication, while Textile Engineering And Manufacturing (T.E.A.M.) of Slatersville, RI provided the T-300 carbon fiber $2 \mathrm{D}$ fabric and $3 \mathrm{D}$ woven textile weaving and preforming for the reinforcement of the silicon carbide matrix composites fabricated by GE PSC. For the second team, Refractory Composites, Inc. (RCI) of Glen Burnie, MD fabricated the $\mathrm{C} / \mathrm{SiC}$ subelements using $\mathrm{T}-300$ carbon fiber fabrics and $3 \mathrm{D}$ woven preforms woven and preformed by Albany International Techniweave (AIT) of Rochester, NH. Southern Research Institute (SRI) of Birmingham, $\mathrm{AL}$ performed non-destructive examination of all of the $\mathrm{C} / \mathrm{SiC}$ composite subelements manufactured by both GE PSC and RCI. Non-destructive examination (NDE) was performed on the $\mathrm{C} / \mathrm{SiC}$ subelements before and after mechanical testing. Government participants in this study have included NASA Langley Research Center (LaRC) for the testing of the $\mathrm{C} / \mathrm{SiC}$ subelements, NASA Dryden Flight Research Center (DFRC) for the combined thermal and mechanical load testing of the $\mathrm{C} / \mathrm{SiC}$ subcomponent, and NASA Johnson Space Center (JSC) for guidance on the re-entry environmental conditions.

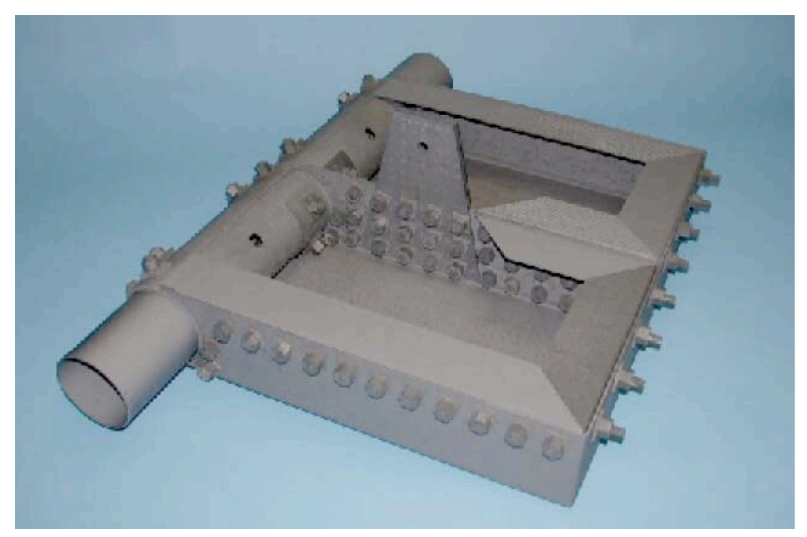

Fig. 7. $\mathrm{C} / \mathrm{SiC}$ body flap subcomponent assembly thermal-mechanically tested at NASA DFRC. 
For the $\mathrm{C} / \mathrm{SiC}$ subcomponent, a half-scale nontapered hot structure body flap, the fabrication was performed entirely by GE PSC with reinforcement woven and preformed by T.E.A.M. Figure 7 shows the $\mathrm{C} / \mathrm{SiC}$ body flap subcomponent designed by MR\&D and fabricated by GE PSC. SRI performed NDE on the $\mathrm{C} / \mathrm{SiC}$ subcomponent prior to testing at NASA DFRC. Posttest NDE was performed by GE PSC using infrared thermography. In addition to coordinating the activities of all of the industry and government participants, MR\&D also performed the material and thermostructural design and analyses of the $\mathrm{C} / \mathrm{SiC}$ components, including each of the $\mathrm{C} / \mathrm{SiC}$ subelements and the $\mathrm{C} / \mathrm{SiC}$ subcomponent.

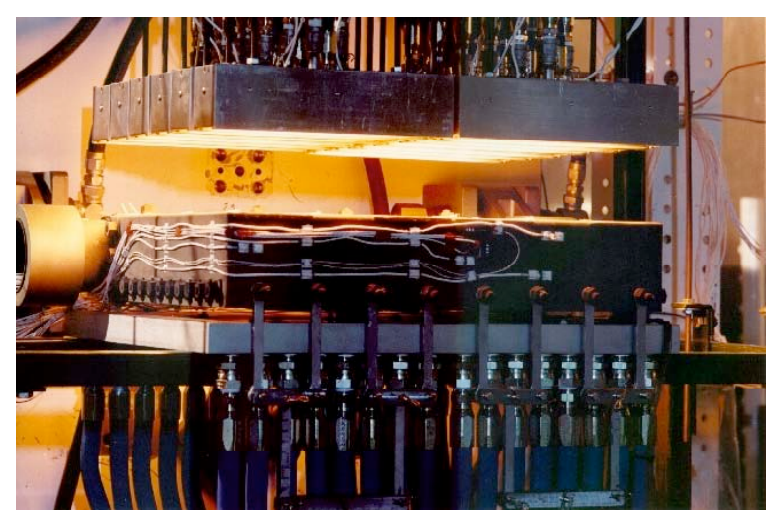

Fig. 8. Photograph of $\mathrm{C} / \mathrm{SiC}$ subcomponent during testing at NASA Dryden.

In November 2003, the $\mathrm{C} / \mathrm{SiC}$ body flap subcomponent was subjected to combined thermal and mechanical testing, by means of simultaneous $2060^{\circ} \mathrm{F}$ heating and 100\% design limit (mechanical) loading (DLL). The simultaneous combined thermal and mechanical testing performed by NASA DFRC was the first combined load testing conducted on a CMC control surface. Figure 8 is a photograph of the body flap subcomponent test article under combined loading at NASA DFRC.

Two additional sub-tasks focused on the applications of $\mathrm{C}<\mathrm{C}$ 's for control surfaces. The first of these focused on the development of integrated hybrid hot structures, comprised of a ceramic matrix composite (CMC) face sheet/insulting foam core/polymer matrix composite (PMC) substructure, which would be loadbearing as well as eliminate the need for an external, parasitic TPS. The second task had as its objective the development of ceramic matrix composites with improved durability under cyclic conditions in oxidizing environments. ${ }^{7}$ Both efforts shared a goal of enabling a wider choice of vehicle flight profiles and increasing operational margin by providing enhanced thermal load capability, and increased safety and reliability, while decreasing vehicle weight.

The Metallic Materials for Airframe Hot Structures task was focused on development of critical technologies for high-temperature metallic materials and incorporating them into generic reusable launch vehicle (RLV) hot structures (see Fig. 9). These hot structures include acreage airframe structure, control surfaces, and thermal protection systems (TPS). In addition, coatings to protect these materials from the service environments and to control heat input into the structures were developed and evaluated.

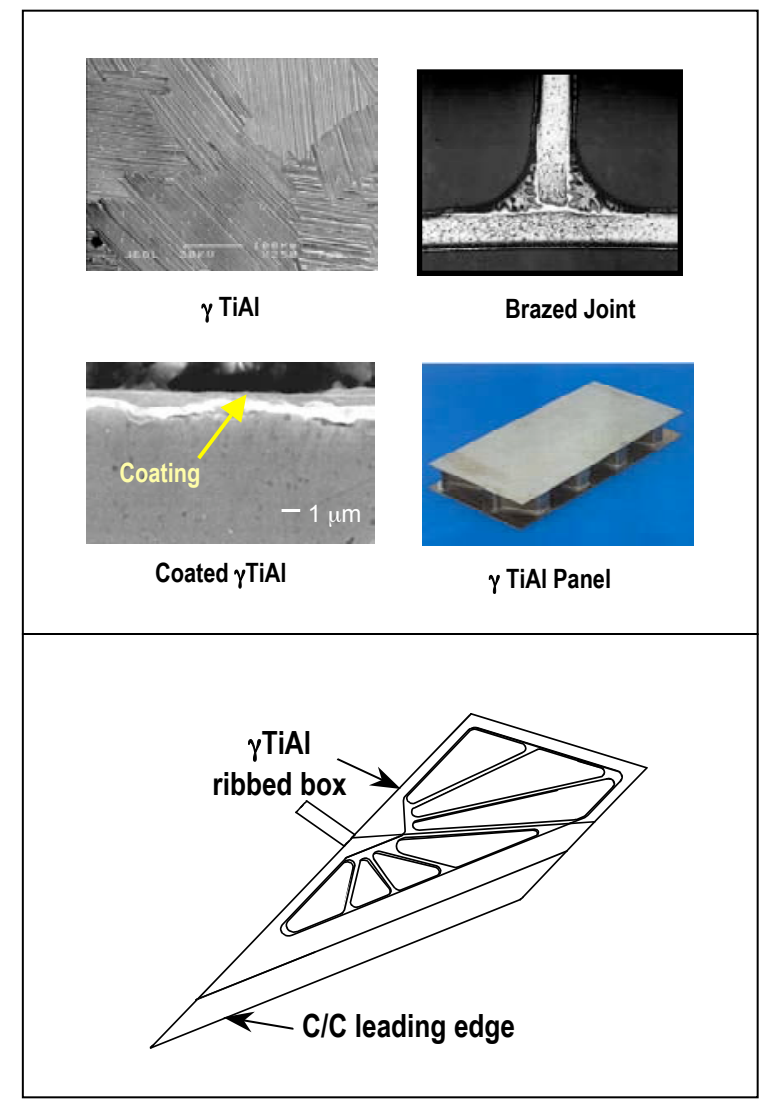

Fig. 9. Technologies investigated for metallic hot structures.

The primary material system of interest was gamma titanium aluminide (TiAl), which had been identified as a high-priority material for future RLVs due to its low density and good properties at temperatures as high as $1600^{\circ} \mathrm{F}$. Advanced oxide dispersion strengthened (ODS) superalloys that have service temperature up to $2200^{\circ} \mathrm{F}$ were also investigated. A small effort was invested in high-risk gamma TiAl metal matrix composites due to their potentially high payoff in terms of low density and excellent high-temperature 
mechanical properties. The task had three primary areas of research: fabrication development, service environment compatibility, and materials development. The fabrication development activity included development of techniques for producing required product forms. These product forms included foil, sheet, plate, extrusions, and near-net shape parts. Powder metallurgy and plasma spray were two technologies that were specifically addressed. Joining techniques were developed to incorporate the candidate alloys into structural concepts. Fabrication processes were evaluated by producing simple structural web elements with face sheets brazed to them. The web cores were fabricated with conventional ingot metallurgy and machining processes and compared to novel near-net-shape powder metallurgy processes.

The service environment compatibility activity involved determination of the service limits of the candidate alloys and developing coatings to protect the alloys from the service environment and to provide thermal control. The coating system of primary focus was an ultrathin sol-gel based multilayered coating. Each layer of the coating is designed to provide one of the multiple functions necessary for a successful coating. The coating was scaled up using spray techniques to coat large components combined with curing by radiant heat lamp arrays that cover large areas.

The materials development activity focused on the correlation and refinement of microstructures, properties, and processing routes for the candidate alloys. In addition, a small effort was investigated for siliconcarbide fiber-reinforced gamma TiAl metal matrix composite development. Due to thermal expansion coefficient mismatch between the fibers and matrix alloy, only very low fiber volume fraction composites were successfully made. Small diameter (0.0004-in.) alumina fibers were also investigated, but their small size made it difficult to achieve reasonable fiber loadings.

The objective of the High-Temperature PMC's task is to utilize advanced polymer science to develop polymeric materials (resins, composites, adhesives) suitable for use in airframe components at temperatures from $-150^{\circ} \mathrm{F}$ to $700^{\circ} \mathrm{F}$ and fully characterize their properties. This will include development and demonstration of high-temperature resistant structural materials, including the development of materials with the proper combination of high- and low-temperature mechanical properties. This task will optimize processability and properties for these high performance materials. Additionally, this task will characterize properties of high- temperature resistant structural materials and develop high-temperature resistant/clay nanocomposites that have improved thermo-oxidative stability. Finally, the determination of failure modes that affect durability of advanced high-temperature structures will be studied by fully characterizing important properties of the hightemperature polymeric materials and understanding the effects of complex loads and environments on materials durability and life.

During the last several years, work has been directed towards the development of technology, specifically materials and processes, for Reusable Launch Vehicles $(\mathrm{RLV})^{8}$. The materials have been designed for non-autoclave processes and a new, non-autoclave process was developed. Eliminating autoclaves from the processing requirements saves costs and allows the production of large structure. The larger the composite fabricated, the lower number of joints required for construction. Reducing the number of joints saves weight and reduces the complexity of the entire structure. With this in mind, an adhesive and composite matrix resin, designated LaRC ${ }^{\mathrm{TM}}$ PETI-8, was synthesized and evaluated. $^{9-11}$ Using a vacuum bag only process with no external pressure, PETI- 8 with a molecular weight of 2500 grams/mole produced excellent adhesive properties. This material is also processable by a newly developed non-autoclave technique referred to as the Double Vacuum Bag (DVB) technique, which provides superior volatiles management to the standard single vacuum bag technique. When the molecular weight is controlled to between 1000 and 1250 grams/mole, the PETI-8 has melt viscosity of 2-3 poise for over 2 hours. This low melt viscosity allows woven carbon fiber composites to be fabricated by vacuum assisted resin transfer molding (VARTM). While aerospace quality high temperature resistant, high performance composites prepared by VARTM have not been successfully fabricated, this material provides an excellent opportunity to meet this goal when fully optimized.

The goal of the Fiber Optic Sensors task is to develop multiparameter and high-temperature optical fiber sensors. The target component for these sensors is both metallic and composite structures. ${ }^{12-13}$ This task builds on the success of X-33 fiber-optic sensor development to develop multiparameter demodulation techniques, and utilize high-temperature coatings and fiber materials to develop high-temperature sensors. 14 The multiparameter sensors will provide single optical fiber strands that provide hundreds of measurements of structural parameters, such as strain, temperature, vibration, chemical environment, etc., that can be embedded or bonded to hypersonic vehicle structural elements 
for in-flight health monitoring. 15 The photograph presented in Fig. 10 shows the optical fiber draw tower at NASA Langley Research Center.

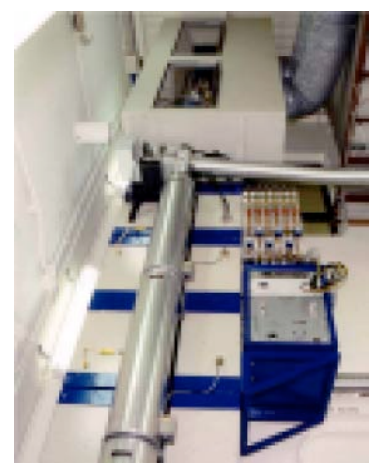

Fig. 10. Photograph of optical fiber draw tower at NASA Langley.

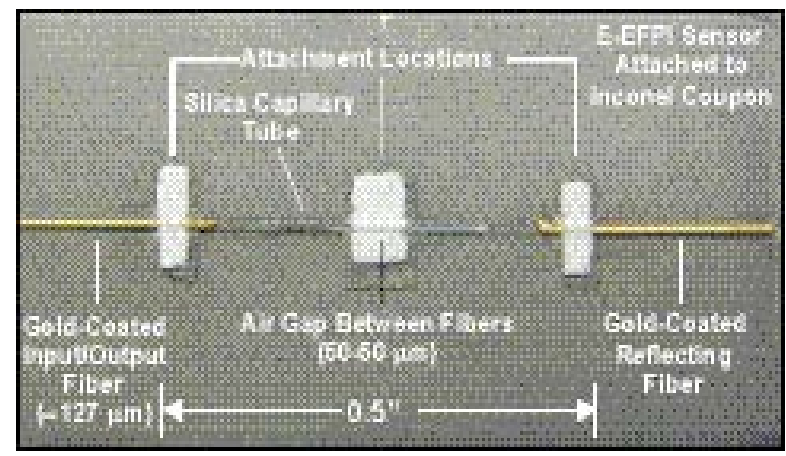

Fig. 11. Details of a high-temperature fiber optic strain sensor installed on an Inconel 601 specimen.

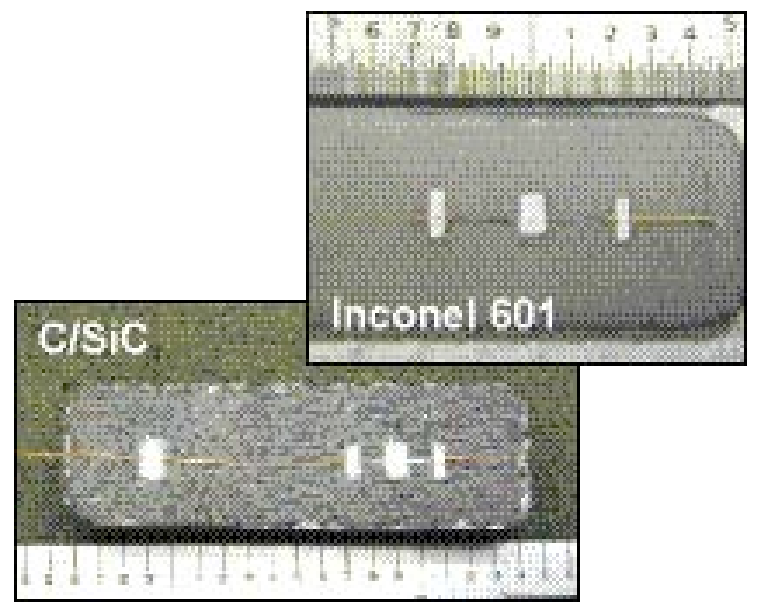

Fig. 12. High-temperature fiber optic strain sensor installed on Inconel 601 and $\mathrm{C} / \mathrm{SiC}$ specimens.

A program has also been established with the goal of developing fiber optic strain sensors with a $3000^{\circ} \mathrm{F}$ temperature capability. ${ }^{16}$ The details of a hightemperature fiber optic strain sensor installed on an Inconel 601 specimen is shown in Fig. 11. Also, a high-temperature fiber optic strain sensor installed on Inconel 601 and $\mathrm{C} / \mathrm{SiC}$ specimens is shown in Fig. 12.

$\underline{\text { Tanks }}$

The Tanks element objectives are the development and demonstration of reusable cyrogenic tanks and is focused on composite and metallic tanks and cryoinsulation. The Composite Tanks task is focused on multiple technologies to advance the use of reusable composite tanks. The Metallic Tanks task is focused on AlLi and advanced alloy metallic tanks, while the Cryoinsulation task is focused on materials development for a high-temperature, sprayable foam insulation.

The objective of the Composite Tanks task is to develop the technology required to design and fabricate full scale, reusable, composite cryogenic tanks. The major activities include (a) materials (validated life prediction tools including permeation, development of $-450^{\circ} \mathrm{F}$ to $550^{\circ} \mathrm{F}$ nonautoclave processable composites and adhesives, and cryo-biaxial life cycling of sandwich panels with in-situ permeation); (b) design and analysis (conformal tank design trades, web joint structural member scaled to reference vehicle, and composite fracture control and residual life tools); (c) fabrication (heat-pipe heat blanket for composite repair and nonautoclave, tow placement fabrication of a $10.5 \mathrm{ft}$ diameter half tank, including post test coupon testing and NDE); and (d) verification (40 LH2 cryo-structural cycles on NG subscale tank, complete cryo testing of $\mathrm{Y}$-joints, cryo-structural testing of conformal tank web joint, and testing of a curved tank panel).

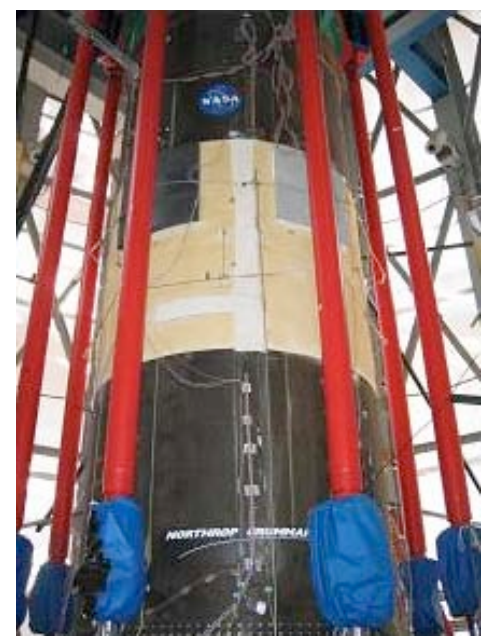

Fig. 13. Six foot diameter, 15 foot long, composite tank in test fixture at NASA Marshall. 
Cryostructural testing of the six-foot diameter composite cryotank has validated the ability of this structure to withstand repeated use in a ground test environment (Fig. 13). The flight weight design has withstood 30 combined pressure and external structural load cycles and continuation of this testing for a total of 40 combined test cycles is planned. The success of this testing and a description of the cryotank design features have been publicized in several industry publications. This technically ambitious achievement is a "centerpiece" of the tank program.

Structural health monitoring (SHM) technology that has been matured throughout the program has been demonstrated on the six-foot diameter subscale composite cryotank. Highlights of this work include the Bragg Fiber Optic sensor arrays that are bonded on the exterior of the composite tank. With this approach, a high density of robust sesors were installed for temperature and strain montoring. Another highlight is the development of display algorithms that permit displaying the entire 3-D teperature and strain response of the structure.

A 78 -inch by 65 -inch curved sandwich panel that represents the sidewall of a 26-foot diameter composite cryotank has been designed, built, and tested (See Fig. 4). This curved cryobox panel has been tested at Langley Research Center in a specially designed test fixture where pressure loads and edge loads were applied under hot and cryogenic temperatures. Thermal protection system (TPS) attachment hardware and insulation was installed on the panel. Metallic TPS is being supplied from another task and thermal-structural analysis has been performed under a separately funded program. This collaborative effort is providing a valuable asset for continued advanced TPS development.

The development of automated layup, UTL compaction, and curing large composite structures outside of the autoclave has culminated in the successful fabrication of a tank section (one half of the cylinder, one dome and skirt) that is nearly half scale. This 10.5 -foot diameter manufacturing demonstration article (Fig. 14) was manufactured at the Alliant Techsystems (ATK) facility in Iuka, Mississippi. This activity provides assurance that large composite cryotank structures can be built within cost and schedule constraints. This half tank structure has been used to demonstrate and validate non-destructive evaluation methods that are suitable for use with the sandwich construction walls of composite cryotank structures.
Y-joint test articles represent a critical area of an Next Generation Launch Technology (NGLT) cryotank being developed by Northrop Grumman Corporation (NGC) and consist of outer skirt and inner dome graphite epoxy composite skin layers bonded to a honeycomb substrate in a sandwich configuration. To enable Integrated Vehicle Health Management (IVHM) of NGLT cryotank concepts, a light-weight multi-sensor technology such as fiber optic distributed Bragg grating strain sensing developed at LaRC is needed as a viable substitute for conventional strain gages which are not practical for this application. This distributed sensing technology uses an Optical Frquency Domain Reflectometer (OFDR) and has the advantage that it can measure hundreds of Bragg graing sensors per fiber and the sensors are all written at one frequency which greatly simplifies manufacturing the fiber. A series of $\mathrm{Y}$-joint tests was conducted over the last two years at LaRC in which optical fibers with bragg gratings were bonded to test articles next to conventional strain gages and strain measurements were taken during loading under cryogenic conditions at $-400^{\circ} \mathrm{F}$ to compare fiber optics to current technology. Cyclic load testing of Cryotank Y-joint test article \#8 at liquid helium temperatures was completed at $\mathrm{LaRC}$ and was the final test in this series. Test article \#8 had been instrumented with three optical sensing fibers on the dome and three on the skirt for comparison to conventional strain gages. Each fiber contained approximately 15 Bragg gratings $10 \mathrm{~cm}$ apart and distributed sensing measurements were performed with an Optical Frequency Domain Reflectometer. Fiber optic strain measurements were performed throughout the 10 test sequences for a total of 400 load cycles simulating NGLT cryogenic fuel tank environments. Each test sequence consisted of cooling the sample from room temperature to $-400^{\circ} \mathrm{F}$ using liquid nitrogen and liquid helium, cycling the dome plate load 40 times from zero to $100 \%$ limit load of 18,360 pounds, then warming back to room temperature. Fiber optic thermal compensation data was obtained through apparent strain testing in which the test article was cooled to liquid helium temperature prior to applying load.

Emphasis on validating robust and maintainable composite airframe structures has extended throughout the entire program. Flat panels representative of cryotank sidewalls that contained intentional defects were built and tested. These disbond arrestment panels demonstrated successful containment of defects. Other tests have been performed with pristine specimens, intentionally damaged specimens, and specimens that contained simulated repairs. The evaluation of composite 
repairs in a cryogenic environment was groundbreaking work.

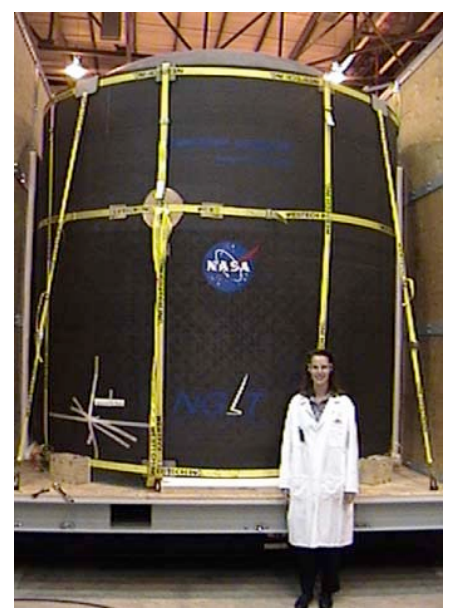

Fig 14. Photograph of $10.5 \mathrm{ft}$ diameter half tank.

NASA Langley led a task with the Boeing Corporation (Boeing), entitled, "Independent Assessment of Boeing Thermal/Structural Optimization of Cryogenic Tanks". In this task, Langley performed an independent assessment of the structural optimization of the barrel section of a composite or metallic cryogenic tank wall, thermal sizing and optimization of the cryogenic insulation and thermal protection system (TPS), design suggestions on the composition of these integrated systems, and combined thermal and mechanical testing of cryogenic insulations on metallic substrates. There was also collaborated on the development of an assessment of cryogenic insulation for both the Boeing and Northrop Grumman Corporations.

The structural optimization work was performed with the University of Florida in Gainesville, FL. They had performed similar optimization studies in the FAST Program $^{17}$ and this data was used in the beginning of the $2^{\text {nd }}$ Gen. RLV Program. ${ }^{18}$ The final product was reported to Boeing in a Task Report and a paper at the ASC 03 Conference. ${ }^{19}$ The structural sizing report was also used in a nonlinear sizing task at LaRC where the thicknesses of the cryogenic and TPS insulations were sized. The sizing of the cryogenic and TPS insulations was presented in a paper at the SDM '04 conference. ${ }^{20}$

A paper was presented at the ASC 03 conference that presented the high temperature results from the testing of material used in the High Speed Research (HSR) Program in RLV temperature environments. ${ }^{21}$ The results from the combined thermal and mechanical testing of cryogenic insulations bonded on metallic substrates for Boeing has been presented. This work was with LaRC personell and compared the degrading of the insulation after being subjected to 50 to 100 thermal and mechanical cycles to pristine insulation. These tests were the longest combined thermal and mechanical cyclic tests to date in the RLV Program. A collaborative effort was also made with LaRC personell to investigate cryopumping in RLV cryogenic insulations. This was the first time cryopumping was measured inside of foam and documented. A paper describing the cryopumping research was presented at the SAMPE 03 meeting. 22

A NASA-Lockheed Martin team successfully performed proof testing and life cycle testing on a one-ofa-kind unlined composite Liquid Oxygen (LO2) tank. At 9.5 feet long, 4.5 feet in diameter and weighing less than 500 pounds, the composite tank represents an 18 percent weight savings over a comparable metal tank. Additional testing on the reusable tank, originally designed and built by Lockheed Martin for the X-34 vehicle, was performed at the Marshall Space Flight Center in Huntsville, Ala. The NASA-Lockheed Martin team put the tank through challenging life cycle tests where the tank is filled with LO2, subjected to multiple pressurizations at limit load, depressurized and drained. Altogether, the tank has completed 52 cycles including 240 pressurizations at cryogenic temperatures. Following life cycle testing, the team hopes to remove the tank from the test stand, obtain barrel membrane coupons to validate the analysis and models, then repair the coupon areas and perform capability testing. NonDestructive Evaluation (NDE) inspections have not shown any changes or degradation in the tank due to life cycle testing.

The objective of the Metallic Tank task is to develop the technology required to design and fabricate full scale, reusable, metallic cryogenic tanks. The major activities include (a) materials (understanding Al alloy delaminations, i.e., what induces delaminations, and can we design around them); and (b) design and analysis (maturing tank life verification strategies by evaluating NDE versus proof test methods).

NASA and Boeing successfully demonstrated the accurate forming of aluminum isogrid panels for future RLV cryotank applications (Fig. 15). The approach was to design, machine, and form isogrid panels with a structurally-efficient T-Cap configuration. The final panel size was $60 \times 84 \times 2$ in. thick, the raw materials included Alcoa 2219 aluminum and Pechiney L277 aluminum-lithium, and the forming radius was $12 \mathrm{ft}$. Post-forming inspection verified the successful demonstration of these innovative designs and low-risk processes. 


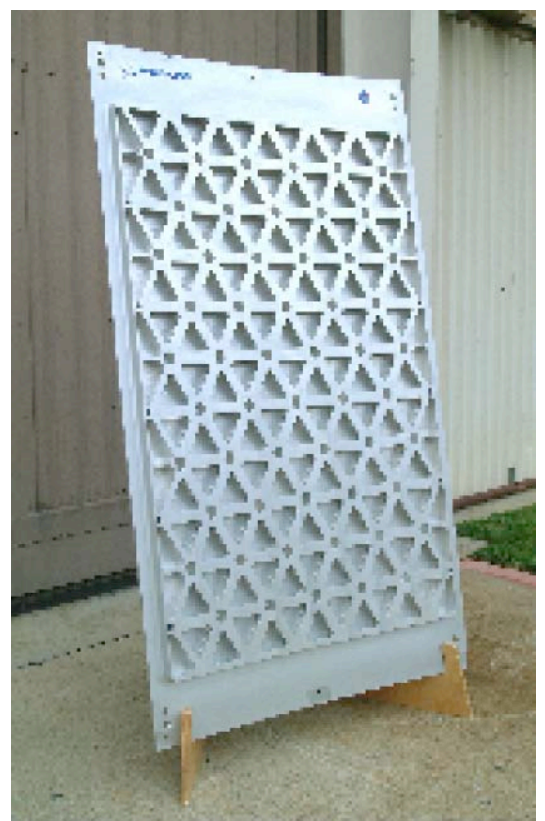

Fig. 15. Aluminum isogrid panel for cryotanks.

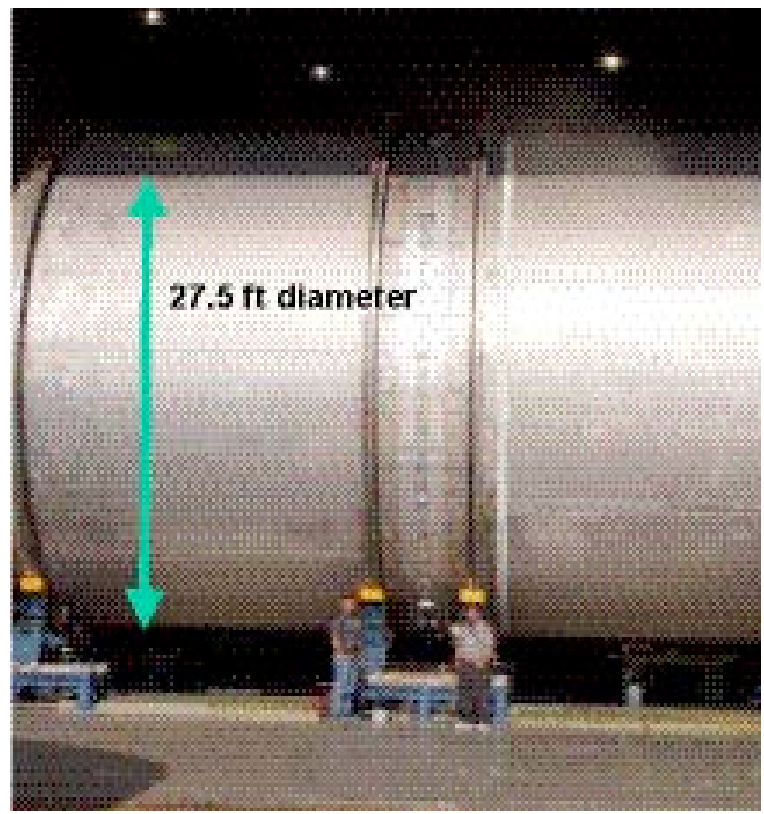

Fig 16. Photograph of $27.5 \mathrm{ft}$ diameter metallic tank sections used for friction stir welding demonstration.

A significant milestone of the Vehicle Systems Research \& Technology Project of NGLT Program was accomplished with the demonstration of a $27.5 \mathrm{ft}$ circumferential self-reacting friction stir weld on a representative metallic cryotank section (Fig. 16). The manufacturing demonstration, which took approximately 90 minutes, went very smoothly with no issues. The circumferential weld will be nondestructively evaluated and samples will be cut from the weld for testing. Friction stir welding has several advantages over fusion welding including improved properties and the ability to join materials that have been considered unweldable. The Self-Reacting Friction Stir Weld process goes further by eliminating the requirements for internal reaction structure, minimizing the axial load imparted to the structure, and solving the through penetration defect issue. The Boeing and NASA team, with support from Lockheed Martin and Morgan Research, accomplished this manufacturing demonstration in only 16 months from authority to proceed.

A NASA-Lockheed Martin-University of New Orleans team collaborated to build a 6 axis robot that fabricated metal tank domes with the self-reacting friction stir welding process (Fig. 17). The demonstration was to reduce manufacturing risk for the fabrication of large metallic domes, which have "complex curvature" or "compound curvature." The dome gore sections are curved and the curvature changes again along the length of the weld. The team successfully welded $22 \mathrm{ft}$ diameter dome sections (intermediate demo) and then 27.5 External Tank dome gore sections for a full scale demo. The TRL was raised to "5.5" for the manufacturing process.

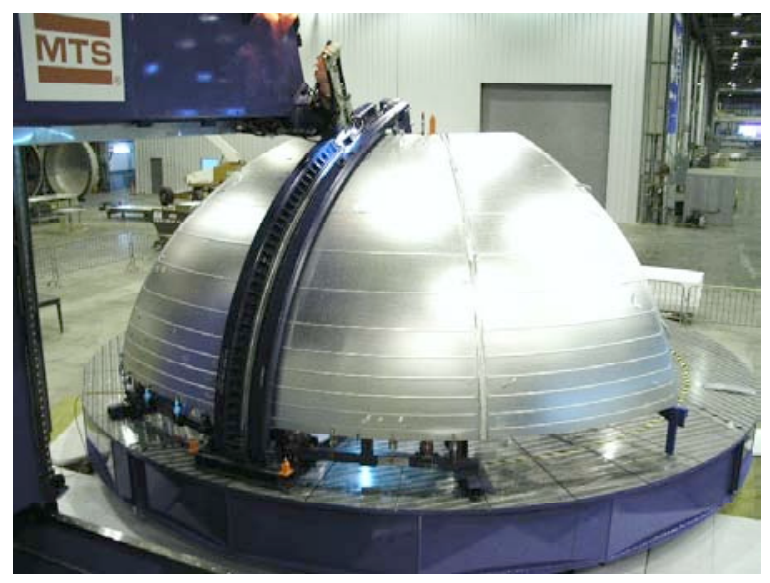

Fig. 17. Schematic diagram of sprayed foam insulation.

Another objective of this task was to conduct metallurgical analysis and mechanical property tests to evaluate candidate metallic materials for reusable cryogenic propellant tank applications. ${ }^{23-24}$ The task conducted an assessment and modification of the expendable Space Shuttle External Tank material Al-Li alloy 2195 for reusable application. In addition, mechanisms associated with delamination fracture in Al-Li alloys were investigated. 
The final tank task is focused on the development of a reusable high use temperature $\left(450^{\circ} \mathrm{F}\right)$ Cryoinsulation that can be applied to complex structures by spray techniques or secondary bonding. This task contains three subtasks. The first will focus on reusable polyimide foam insulation which eliminates cryopumping, developing a process cycle which allows greater than $80 \%$ closed cells for a polyimide foam having a density of $2.0 \mathrm{pcf}$ to $4.5 \mathrm{pcf}$, developing a process cycle which allows foam filled honeycomb to be fabricated without causing degradation to organic honeycomb core, and developing a process to fabricate curved polyimide foam and foam filled honeycomb structures. The second subtask plans to develop a spray-on polyimide foam technique, developing a spray on polyimide foam process cycle which allows application to complex structure (Fig. 18), optimizing the process cycle to produce polyimide foam with more than $80 \%$ closed cells having a density of 2.0 pcf to 4.5 pcf, and fully characterizing physical properties of polyimide foams produced by spray on process. The final subtask will optimize the secondary bonding procedure and characterizing the reusable polyimide foam by developing a process to form strong adhesive bonds between the foam and structure without damaging either.

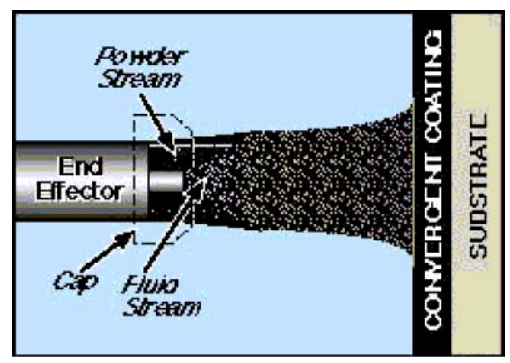

Fig. 18. Schematic diagram of sprayed foam insulation.

In an effort to save RLV structural weight, a high temperature resistant cryogenic insulation was developed. $^{25-29}$ Since the insulation has high temperature capability, it has the potential to substantially reduce the amount of thermal protection system (TPS) required, thereby reducing overall vehicle weight. This newly developed insulation also has excellent properties at cryogenic temperatures allowing it to be used either in or around cryogenic fuel tanks. These materials are nonflammable and nontoxic and have low thermal conductivity and excellent mechanical properties over a large temperature range.

\section{Thermal Protection Systems}

The Thermal Protection Systems element objectives are the development and demonstration of acreage
TPS development of leading edge materials for reuse at high heat fluxes, and development of dynamic seals for control surfaces. To accomplish the objectives, several tasks have been identified. The Metallic TPS task is developing durable metallic TPS for use to $1800^{\circ} \mathrm{F}$. A new task in FY04 is developing a CMC TPS for acreage applications up to $3000^{\circ} \mathrm{F}$. The leading edge task, $3600^{\circ} \mathrm{F}$ Leading Edges, is focused on material development for applications above $3600^{\circ} \mathrm{F}$. The final TPS task is Control Surface Seals and is focused on developing high-temperature seal concepts and verifying performance in simulated environments.

The objective of the Metallic TPS task is to develop and demonstrate a metallic TPS (MTPS) for multi-use on RLVs. This task will focus on two subtasks. The first subtask will evaluate the effect of thermal bowing on the metallic TPS by performing analytical predictions and wind tunnel verification looking at the effect of thermal bowing on boundary layer transition. The second subtask will perform two relevant environment tests on an array of metallic TPS panels. The first test will be a combined thermal acoustic test. A schematic of the test article is shown in Fig. 19. The other test, utilizing the same test article, will be in the 8 $\mathrm{ft}$ High Temperature Tunnel at NASA LaRC and will study the effects of hot gas flow on the MTPS.

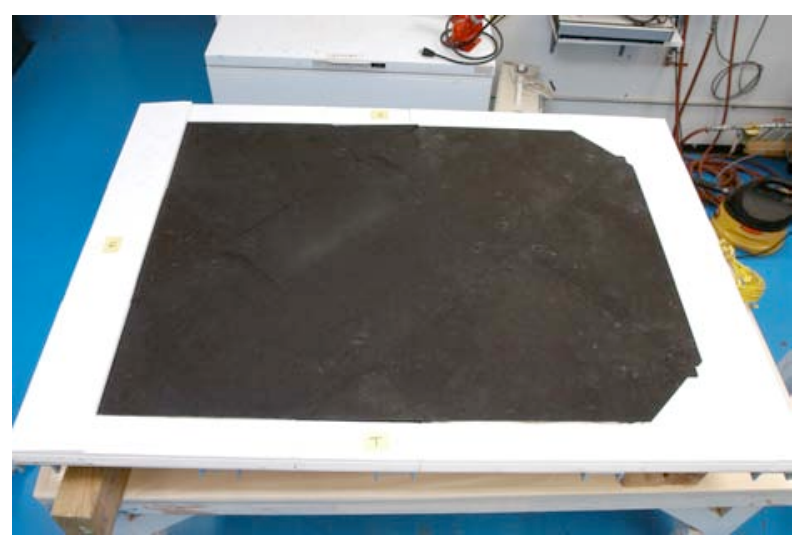

Fig. 19. Photograph of thermal acoustic and $8 \mathrm{ft} \mathrm{High}$ Temperature Tunnel test article.

The objective of the CMC TPS task is to develop and demonstrate a ceramic matrix composite (CMC) TPS for multi-use on RLVs. In the analysis area, this task will identify design loads and requirements, assemble candidate material thermal/structural properties and perform thermal/structural sizing of candidate concepts, obtaining preliminary mass estimates and investigate critical design issues. This task will also perform concept development, identifying candidate concepts, 
considering attachments (Fig. 20), seals, panel size and configuration, and insulation packaging. Finally, prototypes of promising concepts/constituents will be fabricated to investigate attachment concepts, seal configuration, panel removal, etc.

The leading edge task is focused on $3600^{\circ} \mathrm{F}$ Leading Edges, with a goal to develop a composite material system (substrate and coating) for lightly loaded leading edges with a multi-use temperature $>3600^{\circ} \mathrm{F}$. This task will (a) develop carbon fiber reinforce ceramic matrix composites and coatings, (b) develop coatings for $\mathrm{C} / \mathrm{C}$, and (c) develop and verify analytic tools for design and analysis of $\mathrm{C} / \mathrm{C}$ fiber architectures for leading edge applications. A photograph of a test article during arc-jet testing is shown in Fig. 21.

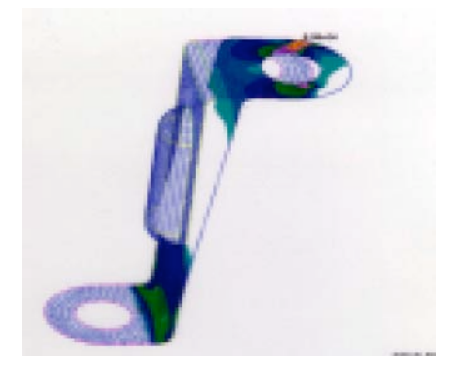

Fig. 20. Finite element analysis of CMC TPS attachment concept.

To support NASA's need for passive refractory composite leading edges with multiple reuse capability at temperatures up to $3600^{\circ} \mathrm{F}$, six material systems were subjected to an expanded arc jet test program. These six material systems had previously survived 3, 130-second cycles in a series of arc jet tests done for the Hyper-X program's X-43A Mach 10 vehicle in 2000. This expanded arc jet test program included three phases. The purpose of the first phase was to generate emissivity data as a function of temperature. The purpose of the second phase was to determine if the material systems had any thermal cycling durability, and the third phase was to determine whether the materials could survive an arc jet test of one hour duration. A summary and conclusions from the expanded arc jet program follow.

$\mathrm{HfC} / \mathrm{HfB}_{2}$ and $\mathrm{Ir} / \mathrm{HfO}_{2}$ coatings had calculated emissivities in the range of 0.25 to 0.58 leading to surface temperature increases of about $1200^{\circ} \mathrm{F}$ compared to RCC at identical arc jet conditions. These low emissivity values make $\mathrm{HfC} / \mathrm{HfB}_{2}$ and $\mathrm{Ir} / \mathrm{HfO}_{2}$ coatings systems unlikely candidates for leading-edge applications. Estimated emissivities of other coatings systems evaluated started at around 0.85 , tended to increase to
0.9 or higher and then dropped off, leading to temperatures slightly lower than RCC at identical arc jet conditions.

Except for the $\mathrm{HfC} / \mathrm{HfB}_{2}$ and $\mathrm{Ir} / \mathrm{HfO}_{2}$ coatings, all other coating systems failed due to the development of a hot spot due to the onset of active oxidation. The onset of active oxidation for the HfC-based coating systems occurred at higher heating rates than single phase silica-based coating systems, indicating that they might be more suitable for certain mission environments.

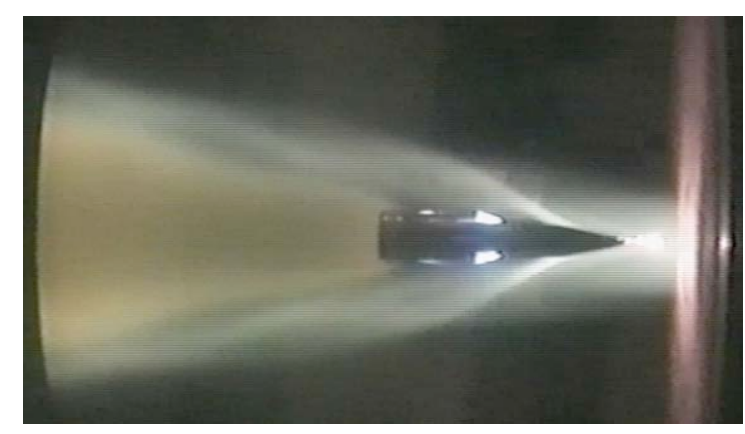

Fig. 21. Photograph of test article during arc-jet testing.

During the cyclic durability phase of the testing, only three materials survived beyond the first cycle. The weight loss seen in the specimens that were tested for cyclic durability indicate that lifetime use of these particular coating systems is limited to only a few missions when the coatings are exposed to maximum temperatures of $3200^{\circ} \mathrm{F}$.

The weight loss of a Refractory Composites, Inc., (RCI) specimen that was subjected to a continuous onehour exposure was much less than the weight loss of the specimen that was thermally cycled, indicating that thermal cycling has a much more detrimental effect on oxidation performance than constant temperature testing. Some abort profiles being investigated require the leading edges to sustain high heat loads for extended times. The fact that the RCI material survived and had low mass loss after a continuous one-hour exposure indicate that there is potential for leading-edge materials to survive this type of abort profile.

The Control Surface Seals task is focused on the development of high-temperature, reusable, resilient seal concepts and the verification of their performance in simulated environments. Current seals on the Shuttle orbiters are designed to work at relatively low temperatures $\left(<1500^{\circ} \mathrm{F}\right)$, while seal temperatures for future vehicles have been predicted to be greater than 
$2000^{\circ} \mathrm{F}^{29}$ The current state-of-the-art (SOA) seal design from the Shuttle orbiters served as the baseline design for this task. This seal consists of an Inconel X750 spring tube stuffed with Saffil batting and overbraided with two layers of Nextel 312 ceramic fibers. Extensive evaluations of this seal revealed that it takes on a permanent set and loses resiliency after exposure to $1900^{\circ} \mathrm{F}$ while in a compressed state as shown in Fig. $22{ }^{29}$ Such a permanent set can cause gaps to form around the seals that allow hot gases to flow past them. In this task, new resilient, high-temperature $\left(2000^{\circ} \mathrm{F}\right)$ control surface seal concepts will be evaluated under representative conditions (temperatures, pressures, scrubbing, etc.).

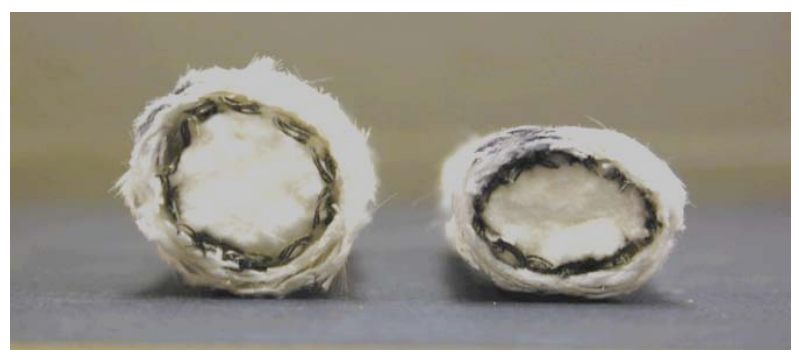

Fig. 22. Current state-of-the-art control surface seals before (left) and after (right) $1900^{\circ} \mathrm{F}$ temperature exposure.

To achieve this, new test rigs have been developed including a hot compression test rig, hot scrub test rig, and a combined room temperature flow and scrub test rig. ${ }^{30-31}$ Both hot compression and hot scrub tests are performed in the same test rig using different test fixturing. A photograph of the hot scrub test fixturing is shown in Fig. 23. Computationally, aerothermalstructural analyses of seals have been performed using tightly integrated CFD-FEA analysis tools. Seal environmental exposure tests will also be performed in an arc jet (Fig. 24).

High temperature compression tests performed on improved spring tube designs showed that a significant improvement in resiliency can be attained by changing the spring tube material from Inconel X-750 to Rene $41 .^{32}$ This material substitution enhanced the maximum use temperature for the spring tube by approximately $275^{\circ} \mathrm{F}$. Other tests revealed that seals with engineered core structures (e.g., smaller rope seals braided or twisted together) should overcome a problem observed on SOA Shuttle seals in which the Saffil batting in the baseline seal has been ejected from the core and lost during flight. ${ }^{31,33}$ Engineered cores are much more likely to remain inside the seal during use. To improve seal durability at high temperatures, oxidation-resistant metal wires were considered as the seal outer sheath material. Oxidation testing in dry air and in water vapor showed that PM2000 and Kanthal A1 wires had much better oxidation resistance at $2200{ }^{\circ} \mathrm{F}$ than other candidate materials. Based on these results, a seal composed of a Rene 41 spring tube with an engineered core and an outer sheath braided out of PM2000 or Kanthal A1 wires would likely be more durable, resilient, and a better flow blocker than the baseline seal design.

As an alternate approach to the baseline springtube-based seal, ceramic wafer seals made of silicon nitride were evaluated. The seals showed no signs of wear or damage after many scrub cycles at temperatures up to $2000^{\circ} \mathrm{F}^{34-35}$ The wafer seals were also excellent at blocking flow with recorded flow rates 32 times lower than those for the best braided rope seals.

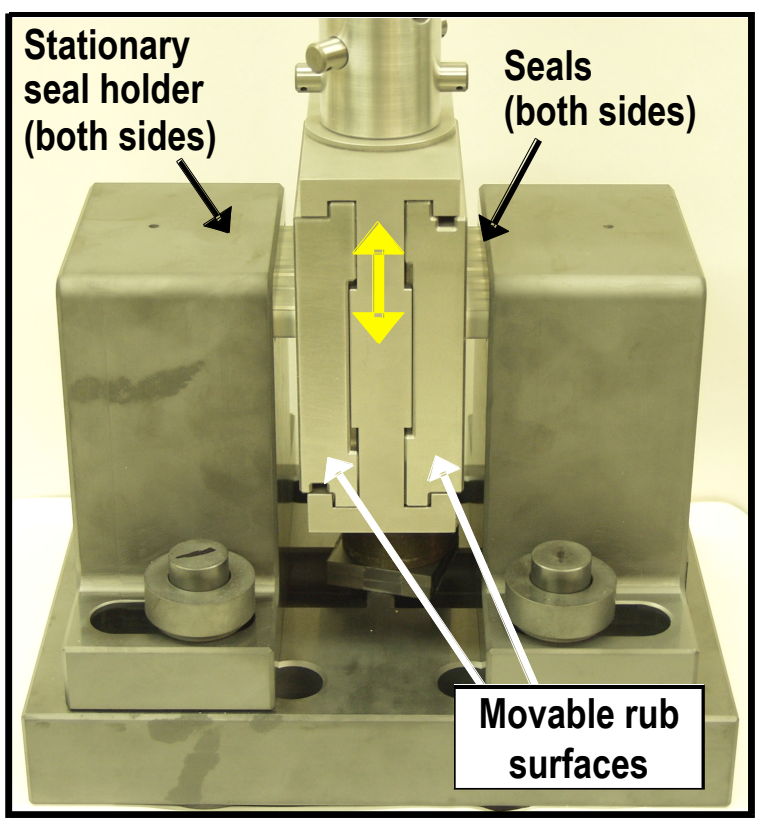

Fig. 23. Photograph of seal hot scrub test rig.

Canted coil springs showed promise as seal preload devices. Room temperature compression tests performed with seals on top of the springs showed substantial improvements in seal resiliency as compared to the seals by themselves. ${ }^{31,35}$ Finite element models of different canted coil spring designs were validated against experimental test results with good agreement in both the load versus displacement curve shapes and magnitudes. ${ }^{35-37}$ These models were then used to design springs out of high temperature wire materials for future seal applications. Silicon nitride compression springs also showed promise as high temperature seal preload devices. After repeated loading at temperatures 
up to $2200^{\circ} \mathrm{F}$ the springs showed little hysteresis and excellent resiliency. ${ }^{34-35}$

To evaluate these new seal designs under simulated reentry heating conditions, a new test fixture has been designed to perform arc jet tests on these seals at NASA JSC (Fig. 24). ${ }^{38}$ This test fixture will have a control surface that can be moved during testing as well as the ability to change the test fixture angle of attack and yaw angle. Different seal designs can be tested in removable cartridges that are installed into the bottom of the test fixture. The test fixture is heavily instrumented to record pressure and temperature drops across the seal in order to evaluate seal performance.

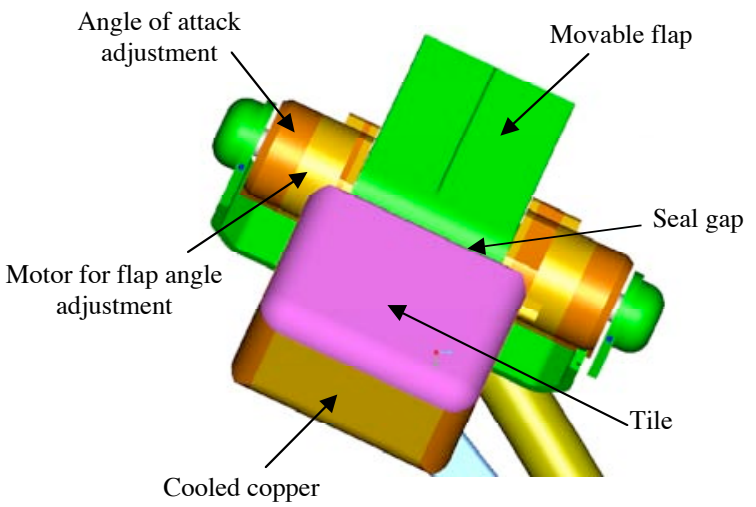

Fig. 24. Model of new seal arc jet test fixture for testing at NASA JSC.

\section{Concluding Remarks}

The Airframe subproject is focused on solving technical challenges confronting NASA's future rocketbased and hypersonic airbreathing-based reusable launch vehicles. These tasks address many of the technical challenges of the vision vehicle and include a mix of low and medium TRL technology. Technical areas being worked include design and analysis tools, hot and integrated structures, cryogenic tanks, thermal protection systems, and integration of various components.

\section{$\underline{\text { Acknowledgments }}$}

Researchers at multiple NASA centers and industry are performing the work in this subproject. Their teaming and hard work is greatly appreciated and is key to the success of both the Airframe subproject and the Next Generation Launch Technology program.

\section{$\underline{\text { References }}$}

1. Stroud, W. Jefferson; Krishnamurthy, T.; and Smith, Steven A.: Probabilistic and Possibilistic Analyses of the Strength of a Bonded Joint. Presented at $42^{\text {nd }}$ AIAA/ASME/ASCE/AHS/ASC Structures, Structural Dynamics, and Materials Conference, AIAA Paper No. 2001-1238, April 1619, 2001, Seattle, WA. Available on CDROM Vol 6, No. 2, AIAA, Reston,VA, 2001.

2. W. Jefferson Stroud; T. Krishnamurthy and Steven A. Smith, "Probabilistic and Possibilistic Analyses of the Strength of a Bonded Joint," Computer Modeling in Engineering \& Sciences, Vol.3, No.6, pp. 755-772, 2002.

3. Stroud, W. Jefferson; Krishnamurthy, T.; Mason, Brian H,; Smith, Steven A.; and Naser, Ahmad S.: Probabilistic Design of a Plate-Like Wing to Meet Flutter and Strength Requirements.. Presented at 43rd AIAA/ASME/ASCE/AHS/ASC Structures, Structural Dynamics, and Materials Conference, AIAA Paper No. 2002-1464, April 22-25, 2002, Denver, CO.

4. Muravyov, A.A. and Rizzi, S.A., "Determination of nonlinear stiffness with application to random vibration of geometrically nonlinear structures," Computers and Structures, Vol. 81, No. 15, pp. 1513-1523, 2003.

5. Rizzi, S.A., "On the use of equivalent linearization for high-cycle fatigue analysis of geometrically nonlinear structures," Structural Dynamics: Recent Advances, Proceedings of the 8th International Conference, Southampton, UK, 2003.

6. Rizzi, S.A. and Przekop, A., "The effect of basis selection on thermal-acoustic random response prediction using nonlinear modal simulation," Proceedings of the $45^{\text {th }}$ AIAA/ASME/ASCE/AHS/ ASC Structures, Structural Dynamics and Materials Conference, AIAA-2004-1554, Palm Springs, CA, 2004.

7. J.G. Smith Jr., H.L. Belvin, E.J. Siochi, R.J. Cano, and N.J. Johnston: Preparation and Properties of a 70/30 Blend of LaRC TMPETI-5/PETI-IAX, High Performance Polymers, Vol. 14, Num. 02, 2002, pp. 209-223.

8. Jensen, B. J.; Lowther, S. E.; Hou, T. H.; Chang, A. C.; Gupta, M. C. and Familant, H.: "Novel Surface Treatments for Bonding Composite Structure," Proceedings of the 27th Annual Meeting of The Adhesion Society, February, 2004, p. 323.

9. Hou, T. H., Cano, R. J., Jensen, B. J., Lowther, S. E., Chang, A. C., and Kellen, C. B.; Processing and Properties of IM7/LaRCTM PETI-8 Polyimide Composites. SAMPE 2004, Long Beach, CA. May 16-21, 2004. 
10 Hou, T. H. and Jensen, B. J.: Evaluation of DoubleVacuum-Bag Process for Composite Fabrication. SAMPE 2004, Long Beach, CA. May 16-21, 2004.

11. Wood, K., Brown, T., Rogowski, R., Jensen B.: "Fiber Optic Sensors for Health Monitoring of Morphing Airframes: I. Bragg Grating Strain and Temperature Sensor". Smart Materials \& Structures, pp. 163-169, 2000.

12. Childers, B.A., Froggatt, M.E., Allison, S.G., Moore, T.C., Hare, D.A., Batten, C.F., Jegley, D.C.: "Use of 3000 Bragg Grating Strain Sensors Distributed on Four Eight-Meter Optical Fibers During Static Load Testing of a Composite Structure". SPIE's 8th Annual International Symposium on Smart Structures \& Materials, March, 2000.

13. Melvin, L., Childers, B., Rogowski, R., Prosser, W., Moore, J., Froggatt, M.E., Allison, S., Wu, M.C., Bly, J., Aude, C., Bouvier, C., Zisk, E., Enright, E., Cassadaban, Z., Reightler, R., Sirkis, J., Tang, I., Peng, T., Wegreich, R., Garbos, R., Mouyos, W., Aidel D., Boden P.: "Integrated Vehicle Health Monitoring (IVHM) for Aerospace Vehicles, Structural Health Monitoring-Current Status and Perspectives". (Edited by: Chang, F.K.) Proceedings of the International Workshop on Structural Health Monitoring, Stanford University, Stanford CA, Technomic Publishing Co. Inc., September 18-20, 1997.

14. Froggatt, M.E.: "Distributed Measurement of the Complex Modulation of a Photoinduced Bragg Grating in an Optical Fiber". Appl. Opt. 35, pp. 5162-5164, 1996.

15. Richards, L., Piazza, A., Parker, A., Hudson, L., Carman, G., Mitrovic, M., Lee, D., Stewart, A.: "Fiber Optic Sensor Development for Structural Health Monitoring of Reusable Launch Vehicles". Proceedings of the 3rd International Workshop on Structural Health Monitoring, Stanford University, Palo Alto, CA, pp. 133-143, September 12-14, 2001.

16. Venkataraman, S., Lamberti, L., Haftka, R. T., and Johnson, T. F., "Challenges in Comparing of Numerical Solutions for Optimum Weights of Stiffened Shells," AIAA Journal of Spacecraft and Rockets, Vol. 40, No. 2, pp. 183-192, Mar.-Apr. 2003.

17. Qu, X., Venkataraman, S., Haftka, R. T., and Johnson, T. F., "Deterministic and Reliability-Based Design of Composite Laminate for Cryogenic Environments", AIAA Journal, Vol. 41, No. 10, pp. 2029-2036, Oct. 2003.

18. Singer, T. N., Qu, X., Haftka, R. T., "Global Optimization of a Composite Tank Structure Using the DIRECT Algorithm," ASC Paper 249, Proceedings of the American Society for Composites 18th
Technical Conference, Gainesville, FL, Oct. 20-23, 2003.

19. Johnson, T. F., Waters, W. A., Singer, T. N., and Haftka, R. T., "Thermal-Structural Optimization of Integrated Cryogenic Propellant Tank Concepts for a Reusable Launch Vehicle," AIAA Paper 2004$1931,45^{\text {th }}$ AIAA/ASME/ASCE/AHS/ASL Structures, Structural Dynamics and Materials Conference, Palm Springs, CA, Apr. 18-22, 2004.

20. Johnson, T. F., and Gates, T. S., "High Temperature Polyimide Materials in Extreme Temperature Environments: High Temperature Results," ASC Paper 103, Proceedings of the American Society for Composites $18^{\text {th }}$ Technical Conference, Gainesville, FL, Oct. 20-23, 2003.

21. Johnson, T. F., Weiser, E. S., Grimsley, B. W., and Jensen, B. J., "Cryopumping in Cryogenic Insulations for a Reusable Launch Vehicle," Presented at the $48^{\text {th }}$ International SAMPE Symposium and Exhibition, Long Beach, CA, May 11-15, 2003.

22. Jata, K.V., Wagner, J.A., Bable, H.W., and Rioja, R.J.: Development of Al-Li Alloy C458 Products for Cryotankage. Presented at the 13th Annual Advanced Aerospace Materials and Processes Conference, Orlando, FL, June 12, 2002. Extended abstract published in proceedings, pg. 80 .

23. Shah, S., Wagner, J., and Bable, H.: Thermal Exposure Effects on Al-Li Alloy Plate Products. Presented at the 14th Annual Advanced Aerospace Materials and Processes Conference, Dayton, $\mathrm{OH}$, June 10, 2003. Extended abstract published in proceedings, pg. 84.

24. Weiser, E. S., Johnson, T. F., St. Clair, T. L., Echigo, Y., Kaneshiro, H., and Grimsley, B. W.; Polymide Foams for Aerospace Vechiles. Journal of High Performance Polymers. pp. 1-12. Vol. 12, No. 1. March 2000.

25. Williams, M. K.; Nelson, G. L.; Brenner, J. R.; Weiser, E. S.,; and St. Clair, T. L.; High Performance Polyimide Foams. Fire and Polymers; Nelson, G. L. and Wilkie, C. A., editors. Chapter 5, 49-62.

26. Roberto J. Cano, Tan H. Hou, Erik S. Weiser, and Terry L. St. Clair: Polyimide Composites From "Salt-Like" Solution Precursors, High Performance Polymers, Vol. 13, Num. 4, December 2001, pp. 235-250.

27. Williams, M. K.; Fesmire, J.; Weiser, E. S.; and Augustynowicz, S.: Thermal Conductivity of High Performance Polyimide Foams. Cold Facts - The Magazine of the Cryogenic Society of America, Inc. Vol. 18 no. 2. Spring 2002.

28. Williams, M. K.; Melendez, O.; Palou, J.; Holland, D.; Smith, T. M.; Weiser, E. S.; and Nelson, G. L.: Characterization of Polyimide Foams after Exposure to Extreme Weathering Conditions. Journal of Adhesion Science Technology. (May 2004). 
29. Dunlap, P.H., Steinetz, B.M., Curry, D.M., DeMange, J.J., Rivers, H.K., and Hsu, S.Y.: "Investigations of a Control Surface Seal for Reentry Vehicles." AIAA Journal of Spacecraft and Rockets, Vol. 40, No. 4, July-August 2003, pp. 570-583.

30. Dunlap, P.H., Steinetz, B.M., and DeMange, J.J.: "Advanced Seal Development at NASA GRC for Future Space Vehicles.” NASA TM-2003-212478, June 2003.

31. Dunlap, P.H., Steinetz, B.M., DeMange, J.J., and Taylor, S.C.: "Toward an Improved Hypersonic Engine Seal.” NASA TM-2003-212531, July 2003.

32. Taylor, S.C., DeMange, J.J., Dunlap, P.H., and Steinetz, B.M.: "Evaluation of High Temperature Knitted Spring Tubes for Structural Seal Applications.” NASA TM-2004-213183, August 2004.

33. DeMange, J.J., Dunlap, P.H., and Steinetz, B.M.: "Advanced Control Surface Seal Development for Future Space Vehicles.” NASA TM-2004-212898, January 2004.

34. Dunlap, P.H., Steinetz, B.M., and DeMange, J.J.: "Further Investigations of Hypersonic Engine Seals.” NASA TM-2004-213188, August 2004.
35. Dunlap, P.H., Steinetz, B.M., and DeMange, J.J.: "High Temperature Propulsion System Structural Seals for Future Space Launch Vehicles." NASA TM-2004-212907, January 2004.

36. Paquette, E.L and Palko, J.: "Hypersonic Airframe and Propulsion Seal Preload Device Development for $2300^{\circ} \mathrm{F}$ Service." Joint Propulsion Conference, July 2004 (AIAA-2004-3888).

37. Oswald, J.J., Dunlap, P.H., and Steinetz, B.M.: Modeling and Evaluation of High Temperature Canted Coil Springs as Seal Preloading Devices. NASA TM-2004-213189, August 2004.

38. Finkbeiner, J.R., Dunlap, P.H., Steinetz, B.M., Robbie, M., Baker, F., and Erker, A.: On the Development of a Unique Arc Jet Test Apparatus for Control Surface Seal Evaluations. NASA TM2004-213204, August 2004.

39. F. I. Hurwitz and R. J. Shinavski, "Alternative Interphase Coatings For Improved Durability In SiC/SiC Composites," Ceram. Eng. Sci. Proc. 24 (4), 231-237 (2003). 